\title{
Removal of Cd (II) Ions from Bioretention System by Clay and Soil Wettability
}

\author{
Tong Xu, Jiacheng Yu, Dongjian Cai, Zhaoyang You (D) and Kinjal J. Shah *D \\ College of Urban Construction, Nanjing Tech University, Nanjing 211800, China; txuaq@connect.ust.hk (T.X.); \\ 201961224028@njtech.edu.cn (J.Y.); 201861224014@njtech.edu.cn (D.C.); youzhaoyang@njtech.edu.cn (Z.Y.) \\ * Correspondence: kjshah@njtech.edu.cn; Tel.: +86-13072541186; Fax: +86-2-23661642
}

\section{check for}

updates

Citation: Xu, T.; Yu, J.; Cai, D.; You, Z.; Shah, K.J. Removal of Cd (II) Ions from Bioretention System by Clay and Soil Wettability. Water 2021, 13, 3164. https://doi.org/10.3390/w13223164

Academic Editor: Antonio Panico

Received: 17 September 2021

Accepted: 9 November 2021

Published: 10 November 2021

Publisher's Note: MDPI stays neutral with regard to jurisdictional claims in published maps and institutional affiliations.

Copyright: (c) 2021 by the authors. Licensee MDPI, Basel, Switzerland. This article is an open access article distributed under the terms and conditions of the Creative Commons Attribution (CC BY) license (https:// creativecommons.org/licenses/by/ $4.0 /)$.

\begin{abstract}
In this work, a silane modifier with benzyl substitutes (OFS-B) and linear substitutes (OFS-L) was used to modify bentonite clay and soil, and the results were characterized by Fourier transform-infrared absorption spectroscopy (FT-IR) and powder-X-ray diffraction (XRD) analysis. A contact angle analysis was performed to determine the wettability of modified clay and soil. The findings revealed that silane-modified OFS-L clay and soil produced wettable surfaces, while OFS-B exhibited hydrophobic properties. These clays and soils were used in a bioretention system for Cd (II) removal. In the study, seven different types of bioretention systems, including natural, OFS-L, and OFS-B modified clay and soil, as well as natural, OFS-L, and OFS-B modified soil, were applied to Cyperus alternifolius plants without an additional layer. The removal capacity of Cd (II) was measured in the following order: modified clay $>$ modified soil $>$ original clay/soil $>$ no layer, i.e., $99.48 \%$, $92.22 \%, 88.10 / 78.5 \%$, and $30.0 \%$, respectively. OFS-L removed more Cd (II) than OFS-B during the modification. OFS-L now improves the bioavailability and accumulation of Cd (II) in the plant $(18.5 \mu \mathrm{g} / \mathrm{g})$ and has a higher chlorophyll-b concentration $(1.92 \mathrm{mg} / \mathrm{g}$ fresh weight $)$ than other systems. The wettable clay exhibited clay leaching into the various levels of the bioretention system. In the bioretention system, benzyl substituted clay prevented the penetration of water and formed a Cd (II) agglomeration. When compared to non-wettable modifiers, these results indicated that wettable clay material could be a capable material for removing Cd (II).
\end{abstract}

Keywords: bioretention; clay; heavy metal; hydrophobicity; silane; soil chemistry

\section{Introduction}

In 2015, the United Nations proposed the Sustainable Development Goals to improve the world's social, environmental, and economic sustainability. The effects of contaminated water are related to Goal 6, clean water and sanitation [1]. Heavy metals are currently the most common pollutants, with a toxic effect on water environments [2]. Point sources such as sewage treatment plants, drainage systems, storm overflows, and surface runoff are responsible for the pollutants introduced [3]. The amount of wastewater discharged from sewage treatment plants and drainage systems is closely monitored. Due to the unpredictability and irregularity of pollutant production, in most cases the amount of wastewater released by rain runoff cannot be controlled or monitored [4]. The most unmanageable source of pollutants that could damage water is rainwater. This rainwater contains 650 different types of organic substances, 30 metals, and several inorganic compounds [3]. Heavy metals, especially zinc, copper, lead, and cadmium, are often discovered [5]. The main sources of these heavy metals are wear and tear and maintenance of vehicles and roads, road asphalt, fuel combustion, car exhaust fumes, and parking dust [6-8]. The presence of heavy metals in precipitation depends on the type of surface, the type and nature of precipitation, and the degree of pollution of the land. Many types of heavy metals are found on urban roads, including cadmium $(\mathrm{Cd})$, copper $(\mathrm{Cu})$, lead $(\mathrm{Pb})$, chromium $(\mathrm{Cr})$, nickel (Ni), and arsenic (As), etc. They enter the rainwater runoff in the form of particles 
or in a dissolved state, and the heavy metals in the dissolved state have the properties of expansion, concealment, hysteresis, and non-degradability. Heavy metals dissolved in water not only destroy the aquatic ecosystem but can also endanger human health by enriching the food chain. Some heavy metals can be toxic to human health, and the risk ratio has been observed in the order $\mathrm{Pb}>\mathrm{Cd}>\mathrm{Cu}>\mathrm{Zn}$ [9].

Heavy metals can be removed using a variety of methods, including bioretention processes [9,10], froth flotation separation processes [11], microbial remediation [12], chemical processing [13], flocculant processes [14,15], and adsorption processes [16,17]. Bioretention, for example, has a significant influence on the removal of heavy metals from rainwater runoff and is often used in the design of green infrastructure [18]. The bioretention system comprises four main steps: sedimentation, filtration, adsorption, and plant uptake $[9,19]$. Heavy metals in particulate form can be easily removed by sedimentation and filtration processes. The adsorption process, on the other hand, removes dissolved heavy metals from rainwater [20]. Dissolved heavy metals are more bioavailable than particulate heavy metals [9,21]. Therefore, it is critical to modernize bio-retention techniques to remove dissolved heavy metals. It has been reported that trees and soil under the pavement have high levels of heavy metal removal in the traditional bioretention system. [4,9]. The presence of heavy metals in the bioretention systems is concentrated in the top $10 \mathrm{~cm}$ [10]. Fom this point of view, the development or modification of the top $10 \mathrm{~cm}$ of the bioretention system can improve the removal capacity.

In addition, many laboratory and pilot scale bioretention systems have shown that the overall efficiency of removing $\mathrm{Zn}, \mathrm{Cu}$, and $\mathrm{Pb}$ from synthetic runoff was typically greater than $95 \%$ [22]. The results obtained suggest that bioretention can be an effective method for improving the quality of urban stormwater runoff [23]. Now the question arises for the case of the mass balance perspective. There are three possible options for optimized removal efficiency [23]. The first is to incorporate $\mathrm{Fe}$ or $\mathrm{Al}$ oxide (sparingly soluble substances) to sequester metals over a long period of time to control their mobility. The second option is to remove the surface layer of the bioretention system, and the third and most important is to promote uptake by selecting appropriate vegetation and harvesting the vegetation regularly to remove heavy metal uptake. There are two types of plants: hyper-accumulator plants and non-accumulator plants [24]. Hyper-accumulators can accumulate 100 times more heavy metals than non-accumulators [24]. In the case of non-accumulator plants, plants with high biomass are coupled with soil conditioning with chelating agents to increase plant uptake [25]. From the above point of view, the importance of the selectivity of the surface layer and the vegetation selectivity is clear.

To develop soil bioaccumulation, organosilanes are often used to produce organically modified soil and clay in order to improve heavy metal binding sites and to adjust the hydrophobicity of soil/clay [26]. In the case of clay, the amount of organosilane loading is generally determined by the cation exchange of the clay and, in the case of soil, by the reactive chemical sites of the soil $[27,28]$. However, a chemical modifier containing benzyl substitutes is chosen in order to obtain desired properties such as hydrophobicity [27]. According to previously published clay chemistry research, the benzyl ring acts as a flat block or tile structure in clay galleries and prevents water from penetrating clay sites [27,29]. Hydrophobic surfaces are created by the type of organic substituents, the degree of surface coverage, unreacted groups, and silane dispersion.

In the current study, aliphatic silane and benzyl-substituted silane were used to modify bentonite clay and red earth. To analyze the changes in physical properties, Flourier transform infrared absorption spectroscopy, X-ray diffraction, scanning electron microscopy, and wettability tests using contact angle measurements and water penetration experiments were carried out. In addition, this silane-modified clay/soil, as well as sand, soil, and gravel, were used as bioretention media to investigate the removal of $\mathrm{Cd}$ (II) heavy metals in synthetic rainwater runoff. Finally, we carried out preliminary tests to determine the influence of silane-modified clay/soils on the yield and quality of Cyperus Corps. To the 
best of our knowledge, no studies have looked at the effects of wettable clay/soil on heavy metal removal in a bioretention system.

\section{Materials and Methods}

\subsection{Materials}

Silane-modified clay and soil for the bioretention system were mixed at high temperature and acidic conditions with or without benzyl substituted silane. Bentonite clay and red soil were purchased from Yuanyuan water purification Co., Ltd. Nanning, China And SanXi mountain soil, respectively. N-Octyltriethoxysilane (OFS-L) $\left(\mathrm{C}_{14} \mathrm{H}_{32} \mathrm{O}_{3} \mathrm{Si}\right)$ and vinylbenzylaminoethylaminopropyltrimethoxysilane (OFS-B) $\left(\mathrm{C}_{17} \mathrm{H}_{31} \mathrm{ClN}_{2} \mathrm{O}_{3} \mathrm{Si}\right)$ were obtained from Nanjing golden chemical Co., Ltd., Nanjing, China. Basic reaction chemicals such as $\mathrm{AgNO}_{3}$, concentrated $\mathrm{HCl}, \mathrm{HF}, \mathrm{H}_{2} \mathrm{O}_{2}$, and Cadmium nitrate tetrahydrate, $\mathrm{Cd}\left(\mathrm{NO}_{3}\right)_{2} \cdot 4 \mathrm{H}_{2} \mathrm{O}$, were purchased from Sinoptico group chemical reagents Co., Ltd., Shanghai, China. All of the chemicals employed in the study were of commercial grade and did not require further purification.

\subsection{Instrumentation and Techniques}

The FT-IR study was carried out using the $\mathrm{KBr}$ pellets technique with the range of 4000 to $600 \mathrm{~cm}^{-1}$ on IRPrestige-21, Shimadzu. To accurately determine d-spacing, clay samples were analyzed using X-ray diffractometer analysis (Bruker D-8 advance). An optical tensiometer was utilized to measure the contact angle of clay and soil samples (Theta attention, Biolin Scientific). A SEM (SU1510, Hitachi) was utilized to examine the surface topography, and EDAX analysis was utilized to determine elemental arrangements (C, K, Al, Si). The presence of $\mathrm{Cd}$ (II) was determined by atomic absorption spectroscopy (AAS) (Z-1000, Enduro) with a detection limit of $9 \mu \mathrm{g} / \mathrm{L}$. Samples (clay/soil) were digested with concentrated $\mathrm{HCl}, \mathrm{HNO}_{3}, \mathrm{HF}$, and $\mathrm{H}_{2} \mathrm{O}_{2}$ for the heavy metal detection experiments. Finally, an ultraviolet absorption spectrophotometer was utilized to measure chlorophyll in the plant (UV 5500).

\subsection{Preparation of Silane Modify Clay/Soil}

Silane modified clay and soil were prepared as in previous work by Shah et al. $[27,29]$ and Gupta et al. [28]. In short, the organoclays/soils were synthesized in the laboratory by condensing clay and soil particles with an aqueous silane material solution (OFS-B and OFS-L) (see Figure 1). The organic silane was dispersed in water at a ratio of 1:10 (silane (ml): water (ml)). Clay and soil were added to disperse silane materials and allowed to react for $45 \mathrm{~min}$ at $40^{\circ} \mathrm{C}$, followed by $\mathrm{pH}$ adjustment to $3-4$ with $\mathrm{HCl}$ and constant stirring for $30 \mathrm{~min}$. The reaction was cooled and stirred for an additional $3 \mathrm{~h}$ to homogenize it. Finally, after allowing the modified samples to sit for $10 \mathrm{~h}$ at room temperature, the supernatant slurry was decanted into separate vessels. The remaining slurry was centrifuged at $2000 \mathrm{rpm}$ for $10 \mathrm{~min}$, and the sediment was dried in an oven at $80^{\circ} \mathrm{C}$ overnight. The bioretention system was built from the silane-modified clay and soil obtained.

\subsection{Set Up of Bioretention Column}

PVC pipe, $7.5 \mathrm{~cm}$ in diameter and $60 \mathrm{~cm}$ height, was used to prepare the bioretention columns (see Figure 2). The layers of gravel, sand, soil, and an additional upper soil/clay layer were conserved to $5,40,9$, and $1 \mathrm{~cm}$, respectively in this study. The gravel, sand, and soil layers were filled gravel 4.75 to $6.3 \mathrm{~mm}$ in size, $1.18 \mathrm{~mm}$ sand: soil (6:4), and $2 \mathrm{~mm}$ sand layer, respectively. The gravel used in this experiment was the type of gravel commonly used in construction. Peat soil, perlite, vermiculite, and carbonized rice hulls make up the soil composition. Cyperus alternifolius is commonly referred to as umbrella grass, which has a grass like clumps of 2-3 fit height and was the type of vegetation used on the superficial bioretention column. This is one of those houseplants that overwatering cannot kill. 


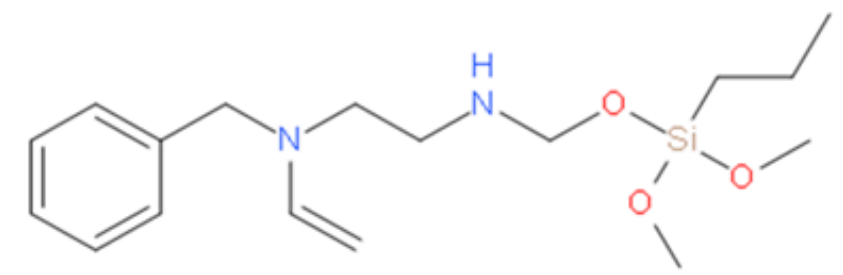

$\left(\mathrm{H}_{2} \mathrm{C}=\mathrm{CHC}_{6} \mathrm{H}_{4}-\mathrm{CH}_{2}-\mathrm{NHC}_{2} \mathrm{H}_{4} \mathrm{NHC}_{3} \mathrm{H}_{6}-\mathrm{Si}\left(\mathrm{OCH}_{3}\right)_{3}\right) \mathrm{HCl}$

Vinylbenzylaminoethylaminopropyltrimethoxysilane (OFS-B)

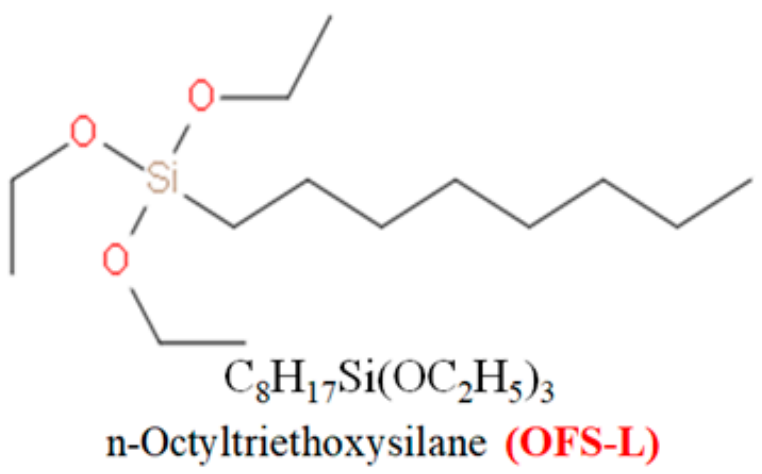

Figure 1. Chemical structure of Silanes.
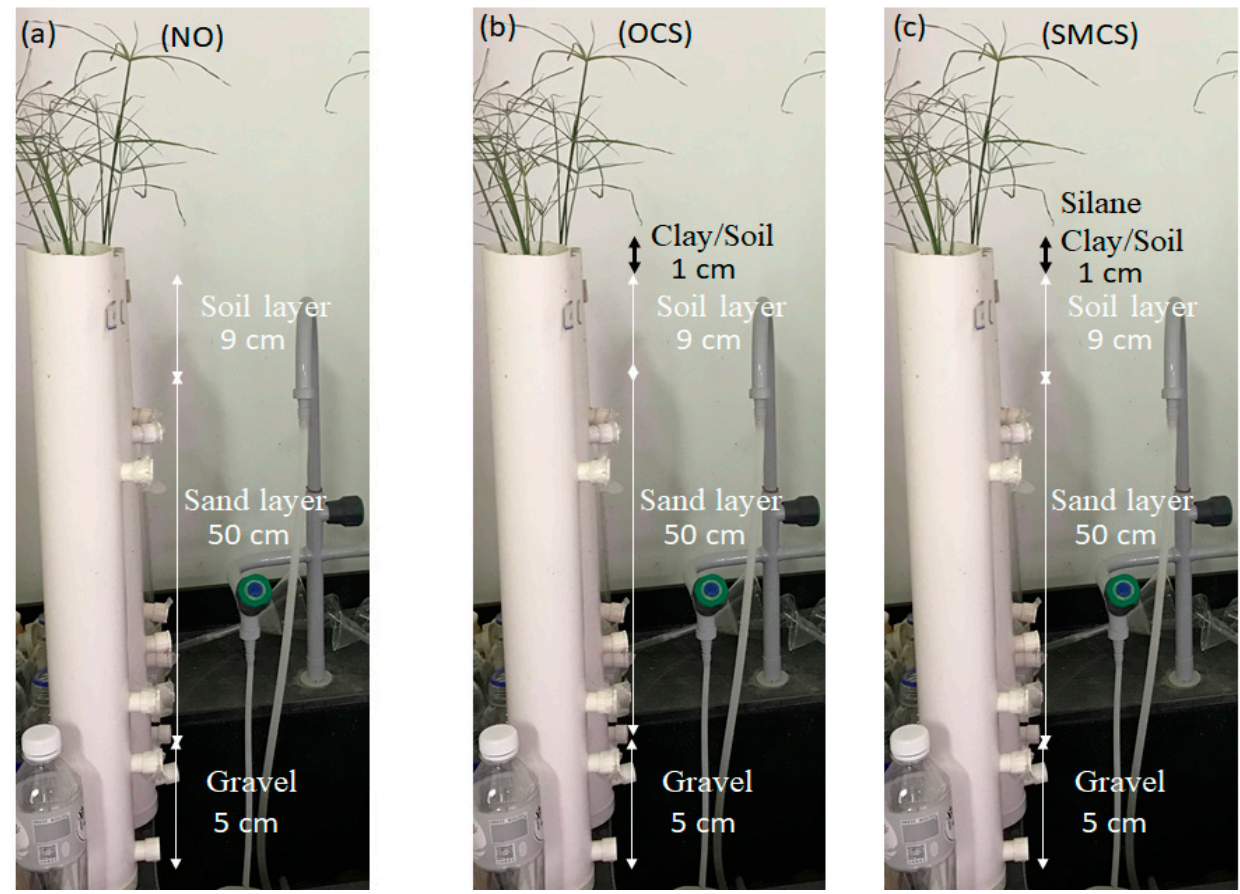

Figure 2. Schematic picture of the various bioretention columns used in this study. Abbreviation (a) NO (without additional layer); (b) OCS (additional layer of original clay and soil); (c) SMCS (additional layer of silane modified clay and soil).

\subsection{Rainfall Simulation and Runoff Calculation}

The primary pollutant in urban runoff are SS, heavy metals, COD, nitrogen, phosphorus, chloride, oil, and pathogenic bacteria. In order to obtain stable raw water, an artificial allocation of simulated raw water was carried out according to the calculation described by You et al. [30]. Table 1 shows the composition and dosage of synthetic water. 
Table 1. Simulated raw water index parameter.

\begin{tabular}{cccccccc}
\hline Indicators & $\mathbf{C O D}$ & $\mathbf{T N}$ & $\mathbf{N H}_{3}-\mathbf{N}$ & $\mathbf{N O}_{3}-\mathbf{N}$ & $\mathbf{T P}$ & $\mathbf{C d}$ \\
\hline Concentration $(\mathrm{mg} / \mathrm{L})$ & 200 & 8 & 5 & 2 & 0.5 & 0.5 \\
\hline Source & $\mathrm{C}_{6} \mathrm{H}_{12} \mathrm{O}_{6}$ & $\mathrm{KNO}_{3}$ & $\mathrm{NH}_{4} \mathrm{Cl}$ & $\mathrm{KNO}_{3}$ & $\mathrm{KH}_{2} \mathrm{PO}_{4}$ & $\mathrm{Cd}_{2}\left(\mathrm{NO}_{3}\right)_{2} \cdot 4 \mathrm{H}_{2} \mathrm{O}$ \\
\hline
\end{tabular}

In general, Nanjing has an annual rainfall of $1256 \mathrm{~mm}$ and an average temperature of $16.1^{\circ} \mathrm{C}$ [31]. There is significant rainfall throughout the year in Nanjing. We simulated rainfall patterns using the Nanjing region rainfall intensity formula (Equation (1)). The runoff coefficient was set to 0.3 , the repetition period to two years, the rainfall duration to $120 \mathrm{~min}$, the catchment area ratio to $5 \%$, and the repetition period to two years (road runoff coefficient).

$$
q=\frac{10716.700(1+0.837 \ln p)}{(t+32.900)^{1.011}}
$$

where $q=83.02 \mathrm{~L} /\left(\mathrm{s} \mathrm{hm}^{2}\right)$ is the rainfall intensity, $p$ is the return period (a), and $t$ is the rainfall duration $(\mathrm{min})\left(\mathrm{s} \mathrm{hm}^{2}\right)$.

The design rainwater flow is calculated by following formula:

$$
Q_{s}=q \psi F+q f
$$

where $Q_{s}$ is the design discharge $(\mathrm{L} / \mathrm{s})$, $\mathrm{q}$ is rainfall intensity $\left(\mathrm{L} /\left(\mathrm{s} \mathrm{hm}^{2}\right)\right), \psi$ is the runoff coefficient, $F$ is the catchment area $(\mathrm{hm})$, and $f$ is the plant surface area $(\mathrm{hm})$. The experimental column in this experiment was $7.5 \mathrm{~cm}$ in diameter; $F=883.58 \mathrm{~cm}^{2}$ and $Q s=2.57 \times 10^{4} \mathrm{~L} / \mathrm{s}$ were computed, resulting in a total volume of influent water of $1.15 \mathrm{~L}$ after two hours.

After calculating the water, three systems were installed (see Figure 2), one without an additional layer (Figure 2a), one with untreated clay and soil (Figure 2b), and one with a silane-modified clay and soil incorporated system (Figure 2c). After all the systems were installed, the test columns were rinsed with tap water (each test column was reported by $2 \mathrm{~L}$ at a time, twice a day, for 4 days) to allow the water to flow from the top down in the test column and between the layers. After the scour was complete, the bio-retention column was flushed with simulated rainwater (three times a day) to obtain saturation.

The experimental water intake was then carried out on the first and third days, with $1.15 \mathrm{~L}$ of simulated rainfall being fed to the experimental column for $2 \mathrm{~h}$ using a peristaltic pump. On the seventh day, after a period of three days, water was again injected into the sample. Finally, a seven-day drying period was framed, with water intake, water sampling, and soil sampling taking place on the fifteenth day. After each flow, water samples were collected for the analysis. In addition, through the sampling holes, soil samples from each layer were collected. Finally, after a 15-day experiment, plant samples were taken to determine heavy metal uptakes and chlorophyll content.

\subsection{Yield and Quality of Cyperus Alternifolius}

Finally, the presence of Cd (II) and Chlorophyll-b tests were performed on Cyperus alternifolius to identify initializing plant quality experiments, Cyperus was divided into three different components, i.e., leaves, stem, and roots. All three components were carefully cleaned with deionized water numerous times before being dried in the oven at $70{ }^{\circ} \mathrm{C}$. The dried materials were crushed and digested with concentrated $\mathrm{HNO}_{3}$ and $\mathrm{H}_{2} \mathrm{O}_{2}$ before being subjected to the heavy metal identification procedures described by Chen et al. [32]. The content of the chlorophyll-b test of leaves, as described by Arnon's method [33], can be utilized to determine the plants 'survival. A $50 \mathrm{~mL}$ colorimetric tube was filled with $0.1 \mathrm{~g}$ of dried leaf sample. Then, $25 \mathrm{~mL}$ of acetone was added and shaken thoroughly for $10 \mathrm{~min}$ before filtration. An ultraviolet spectrophotometer was utilized to measure the filtrate at a wavelength of $645 \mathrm{~nm}$ (chlorophyll b). 


\section{Results}

Silane-modified clay and soils for the bioretention system were mixed at high temperature and acidic conditions, with or without benzyl substituted silane. The physico-chemical properties after modification and their applicability for bio-retention systems were determined in this section.

\subsection{Characterization of Silane Modified Clay and Soil}

FT-IR analysis can demonstrate the presence of modifiers on the clay and soil surfaces. Figure S1 shows the FT-IR absorption spectra of pristine and silane-modified clay and soils. For soil and clay samples, bands in the $3700-3500 \mathrm{~cm}^{-1}$ and $1034 \mathrm{~cm}^{-1}$ ranges were ascribed to the $-\mathrm{OH}$ stretching vibration area of the $\mathrm{Me}-\mathrm{OH}(\mathrm{Me}=\mathrm{Si}, \mathrm{Mg}$, or $\mathrm{Al})$ group and the stretching vibration of structural silicate groups, respectively, for soil and clay samples [27]. The $-\mathrm{OH}$ bending mode is represented by a band at $1635 \mathrm{~cm}^{-1}$, whereas the $\mathrm{Si}-\mathrm{O}-\mathrm{Si}$ stretching vibration and the vibration mode of $\mathrm{Me}-\mathrm{O}-\mathrm{Me}^{\prime}$ ( $\mathrm{Me}$ and $\mathrm{Me}^{\prime}=\mathrm{Si}, \mathrm{Mg}$, or $\mathrm{Al}$ ) are represented by bands at 1114 and $907 \mathrm{~cm}^{-1}$, respectively. The peak at $700 \mathrm{~cm}^{-1}$ represents quartz, with a higher intensity in the soil sample indicating a higher amount of quartz in the soil sample [34].

All characteristic bands of clay and soil samples were retained after the silane conversion. Additional bands were found at 2924 and $2848 \mathrm{~cm}^{-1}$, which were attributed to the silane modifiers $-\mathrm{CH}_{2}$ stretching vibration [35]. In addition, an extra silicate group of silane modifiers [36] boosted the intensity of the peak $1034 \mathrm{~cm}^{-1}$. The presence of a silane group on the surface of the soil and clay is confirmed by this increase. An additional spectral peak at $1470 \mathrm{~cm}^{-1}$ in the FT-IR spectra of silane-modified clay and soil, OFS-B modified clay and soil, and soil shows the existence of benzyl substituents [37]. However, no additional peak of the $\mathrm{N}-\mathrm{H}$ group was observed owing to the weak intensity of the present group. The FT-IR results obtained confirm the presence of silane modifiers on the surfaces of soil and clay. In order to identify silane modifiers in the layer spacing (d-spacing) of clay, XRD analysis was performed. The d-spacing values of original clay and silane-modified clay samples are shown in Table 2. The addition of a silane modifier resulted in an increase in d-spacing values, as expected. Benzyl substituted silane (OFS-B) exhibited a higher $\mathrm{d}$-spacing because the benzyl group was present inside the clay layers. The presence of a silane modifier in the clay interlayer is confirmed by the d-spacing data.

Table 2. d-spacing and contact angle of silane modified/unmodified clay and soil samples.

\begin{tabular}{cccc}
\hline No & Sample & d-Spacing $(\AA)$ & Contact Angle $\left(^{\circ}\right)$ \\
\hline 1 & Clay & 14.6 & 76 \\
\hline 2 & Clay OFS-B & 18.3 & 125 \\
\hline 3 & Clay OFS-L & 16.2 & 81 \\
\hline 4 & Soil & - & 120 \\
\hline 5 & Soil OFS-B & - & 145 \\
\hline 6 & Soil OFS-L & - & 123 \\
\hline
\end{tabular}

Basic physico-chemical properties can be altered by changing the geometry of clay and soil after the change. The contact angle of the samples was measured, and the findings are shown in Table 2. The contact angles of the original clay and the original soil were $78^{\circ}$ and $120^{\circ}$, respectively. According to the results, the soil is more hydrophobic than clay because of its spear structure. Clay, on the other hand, has a layered structure that traps water within the interlayer. When benzyl substituted (OFS-B) silane was compared to liner (OFS-L) silane, the contact angle increased dramatically. The benzyl substitution resisted water in the clay structure by preventing interlayer (d-spacing) spacing and soil structure by higher-stacking (stearic) effects [29]. The results indicate that, after using OFS-B and OFS-L silane modifiers, variation in clay and soil physicochemical parameters occur. In 
addition, when compared to soil-OFS-L, the super-hydrophobic character of soil-OFS-B was detected.

\subsection{Removal of Cd (II) from Bioretention System}

In order to investigate the applicability of organoclay for the Cd (II) removal, adsorption experiments were carried out with different rainfall intervals in order to simulate the Cd (II) uptakes.

Figure 3 shows the Cd (II) removal rate in the bioretention system utilizing OFS-L modified clay and soil samples over rainfall intervals. NO represents a typical bioretention system without adding any clay or soil. The clearance rate of $\mathrm{Cd}$ (II) increased at first and then declined after 7 days, as seen in the graph. On the third day, the removal rate of $\mathrm{Cd}$ (II) by OFS-L modified clay reached a maximum of $98.3 \%$, then stabilized at above $80 \%$ in the samples. The OFS-L modified soil displayed the second highest adsorption on the third day. Meanwhile, the removal rate for bioretention systems with no extra layer, i.e., NO, was the lowest. Furthermore, the removal rate of NO samples remained nearly constant when compared to the other two types of systems. The reason for this is that the OFS-L modified clay and soil system has a larger interlayer spacing, implying more interaction space. For the same reason, clay and soil samples are analyzed. Clay has a comparatively larger layer space than soil. The reason for the increased amount of removal for day 3 is the occupation of available free sites. Bioretention systems were dried on the first day but were wet on the third day due to rain. Swelling may be visible in different samples throughout this time. This swelling allows Cd (II) to be removed from the clay [27]. The binding sites for the Cd (II) in soil are provided by the arrangement of modifiers on surfaces.

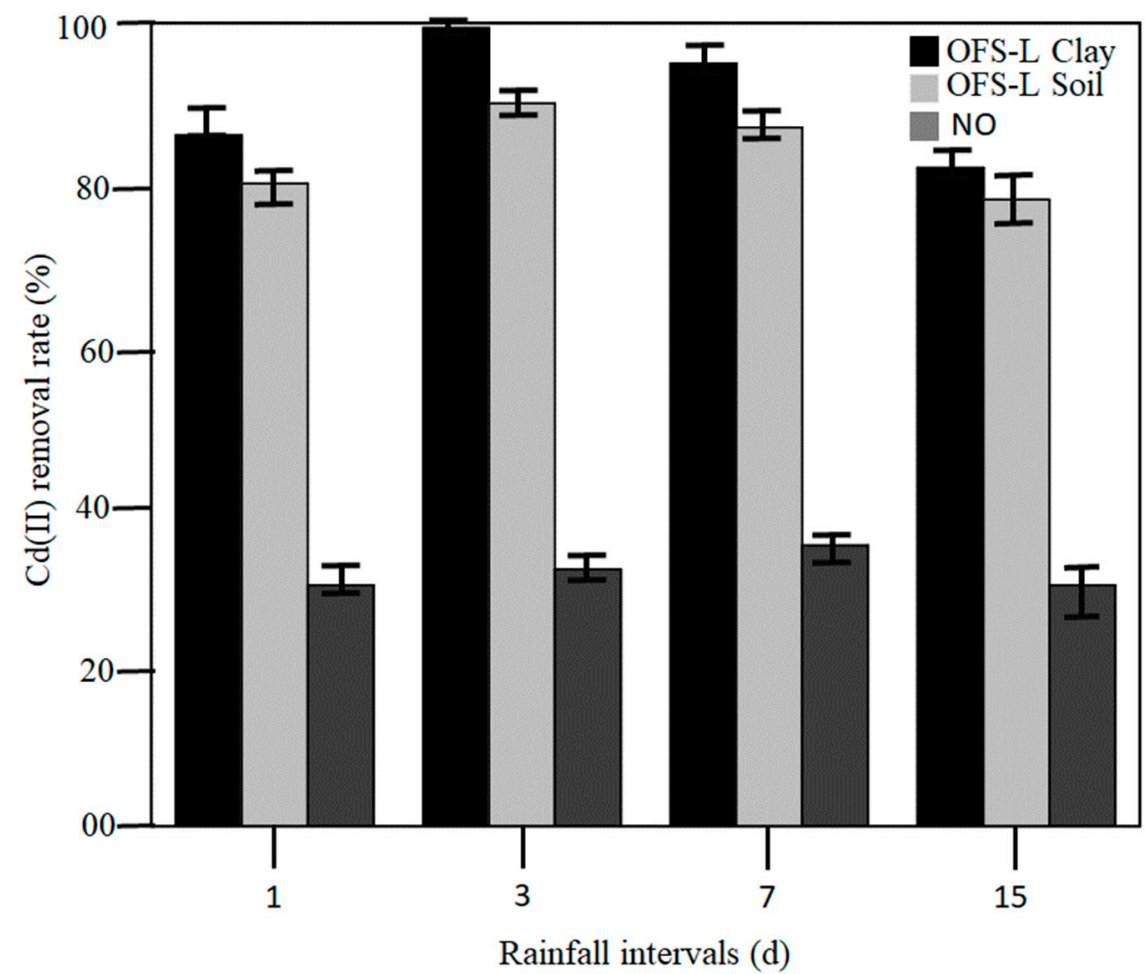

Figure 3. Removal rate of Cd (II) by bioretention system against rainfall intervals (days).

The tendency of each bioretention system was studied after confirming the optimal day for adsorption, and Cd (II) removal rates of all systems on day 3 are shown in Figure 4 . The removal rates of $\mathrm{Cd}$ (II) of the seven bioretention systems are separated into four groups, as shown in the Figure 4 modified clay, modified soil, original clay/soil, and NO (no additional layer). Cd (II) removal capability was the highest among them in the case of a clay system. Modified clay $>$ modified soil $>$ original clay/soil $>\mathrm{NO}$ is the order of 
adsorption rate. The reason for this is that the modified clay used in bioretention systems contains a liner silane modifier with a greater interlayer spacing than soil and original clay samples. This finding demonstrates that adding clay or modified clay to a bioretention system improves the adsorption and removal of Cd (II). The OFS-L modified clay has a higher adsorption capacity than the OFS-B modified clay when the silane modifier effect is compared. In the case of changed soil systems, a similar occurrence was also seen. The phenomenon is noticed when Cd (II) enters the system. Wettable (hydrophilic) clay begins adsorption in its interlayer before moving on to the next layer. The penetration rate of non-wettable (hydrophobic) clay is prolonged in the competition. As a result, it can be inferred that simply adding a modified clay layer to a bioretention system is a superior application strategy and has a better effect on Cd (II) removal. Furthermore, hydrophilic clay is found to be more suited for bioretention systems.

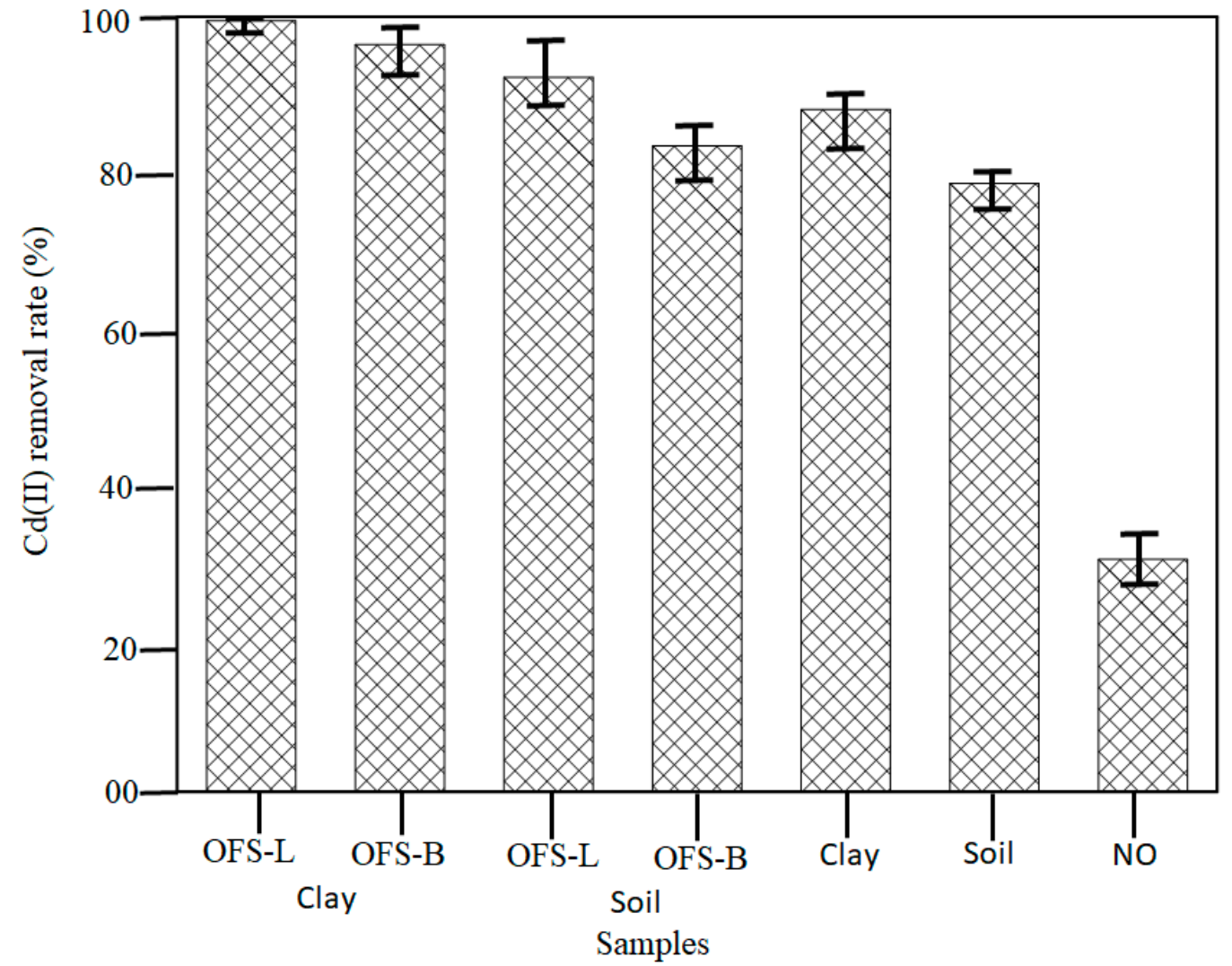

Figure 4. Cd (II) removal rates on day 3 of bioretention system using clay and soil samples.

\subsection{Mobility and Adsorption of Cd (II) in Each Layer of Bioretention System}

In order to determine the amount of Cd (II) adsorption in each layer, soil, clay, sand, and gravel samples were tested. Changes in Cd (II) content were seen in each section of the bioretention layer (a) extra layer $(1 \mathrm{~cm})$, (b) soil layer $(9 \mathrm{~cm})$, (c) sand layer $(50 \mathrm{~cm})$, and (d) gravel layer $(5 \mathrm{~cm}$ ) (as shown in Figure 5). When comparing all four layers, the Cd (II) adsorption can be found to be in the order layer I > layer II > layer III > layer IV. The acquired result confirms that binding sites in each layer play a critical role. The sand, soil, and clay layers have a larger surface area and more binding sites than the gravel layer. Furthermore, silane-modified clay/soil contains more binding sites and possibly more adsorption capacity than unmodified clay/soil. There were six systems in the case of the additional layer. The "NO" system is missing because it lacks an additional layer. OFS-L clay $>$ clay $>$ OFS-B clay > OFS-L soil > soil > OFS-B soil is the order of Cd (II) adsorption. The findings demonstrate that adsorption occurs in the order of their wettability. The hydrophobic behavior of OFS-B modified clay/soil prevents water from penetrating the bioretention system, causing agglomeration. 

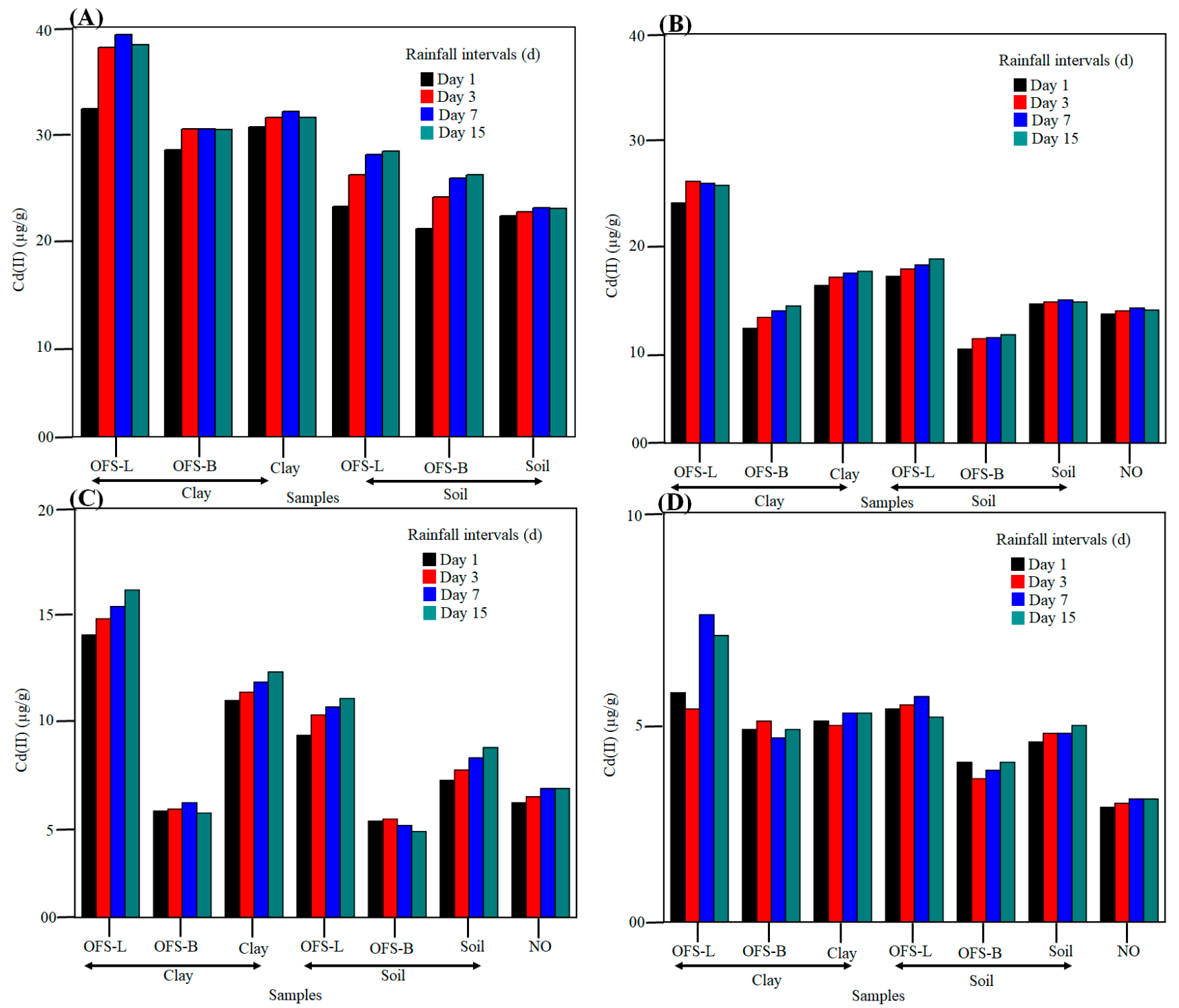

Figure 5. Concentration of Cd (II) in each section of bioretention layer (A) additional layer I (1 cm), (B) soil layer II (9 cm), (C) sand layer III $(50 \mathrm{~cm})$, and (D) gravel layer IV $(5 \mathrm{~cm})$.

Hydrophilic clay/soil, on the other hand, displays water penetration in the bioretention system, resulting in heavy metal leaching in the interlayer, and also downwards in the bioretention system. The soil layer is layer II. We may compare 7 bio-retention systems, including NO, in this article. OFS-L clay $>$ OFS-L soil $>$ Clay $>$ Soil $>$ NO $>$ OFS-B clay $>$ OFS-B soil is the order of Cd (II) removal. In comparison to the hydrophobic nature, the acquired data support the hydrophilic nature. The transmission or exchange of heavy metal from each layer is the primary reason for this. Furthermore, because of the larger interlayer gap, hydrophilic clay has a higher propensity for passing Cd (II). Layer III and layer IV followed a similar pattern. Furthermore, the rate of Cd (II) elimination on day 7 is larger than on other days. The reason for this is because most Cd (II) will be leached from layer I to layer III during the next two wet days, namely days 1 and 3. The majority of Cd (II) has time to settle over the layer surfaces during a four-day interval, however. Higher drying times, on the other hand, cause agglomerates and, as a result, creaks in the bio-retention system, resulting in lower Cd (II) removal capacity.

Beyond all of these studies, an additional layer of wettable OFS-L clay was found to be the most effective modifier for removing Cd (II) from the bio-retention system. The preceding findings demonstrate that the OFS-L and OFS-B modifiers have a considerable impact on the removal's final attributes. 


\subsection{Cd (II) Uptakes and Accumulation in Cyperus Alternifolius Plants}

Figure 6 shows the effect of silane-modified clay/soil on Cd (II) uptake and accumulation in plant tissue. The base of the plant had the highest concentration of $\mathrm{Cd}$ (II) compared to the stem and leaf. Meanwhile, the order of Cd (II) adsorption is clay $>$ soil $>\mathrm{NO}$. The lack of binding sites or extra sites can be blamed for the lower Cd (II) concentration. When compared to soil, clay has a larger surface area and more binding sites. There is no extra layer for $\mathrm{NO}$, which clearly demonstrates the influence of accessible binding sites for $\mathrm{Cd}$ adsorption (II). Cd (II) adsorption is significantly improved after the hydrophilic OFS-L and hydrophobic OFS-B silane-modifiers are added to the clay and soil samples. In the case of Root, the adsorption is modified Clay $>$ modified soil in that sequence. OFS-B clay $>$ BFS-B soil > soil > OFS-L clay > OFS-L soil > clay. According to the findings, the OFS-L are responsible for increased Cd (II) adsorption in the stem and leaf. Meanwhile, the capillary effect is thought to be responsible for the vegetative uptakes, which indicates OFS-B could restrict the edges of plants. The capillary effect and Cd (II) adsorption in the stem and leaf could be reduced as a result. Due to the presence of OFS-B near the margins, agglomeration or colloid formation is common.

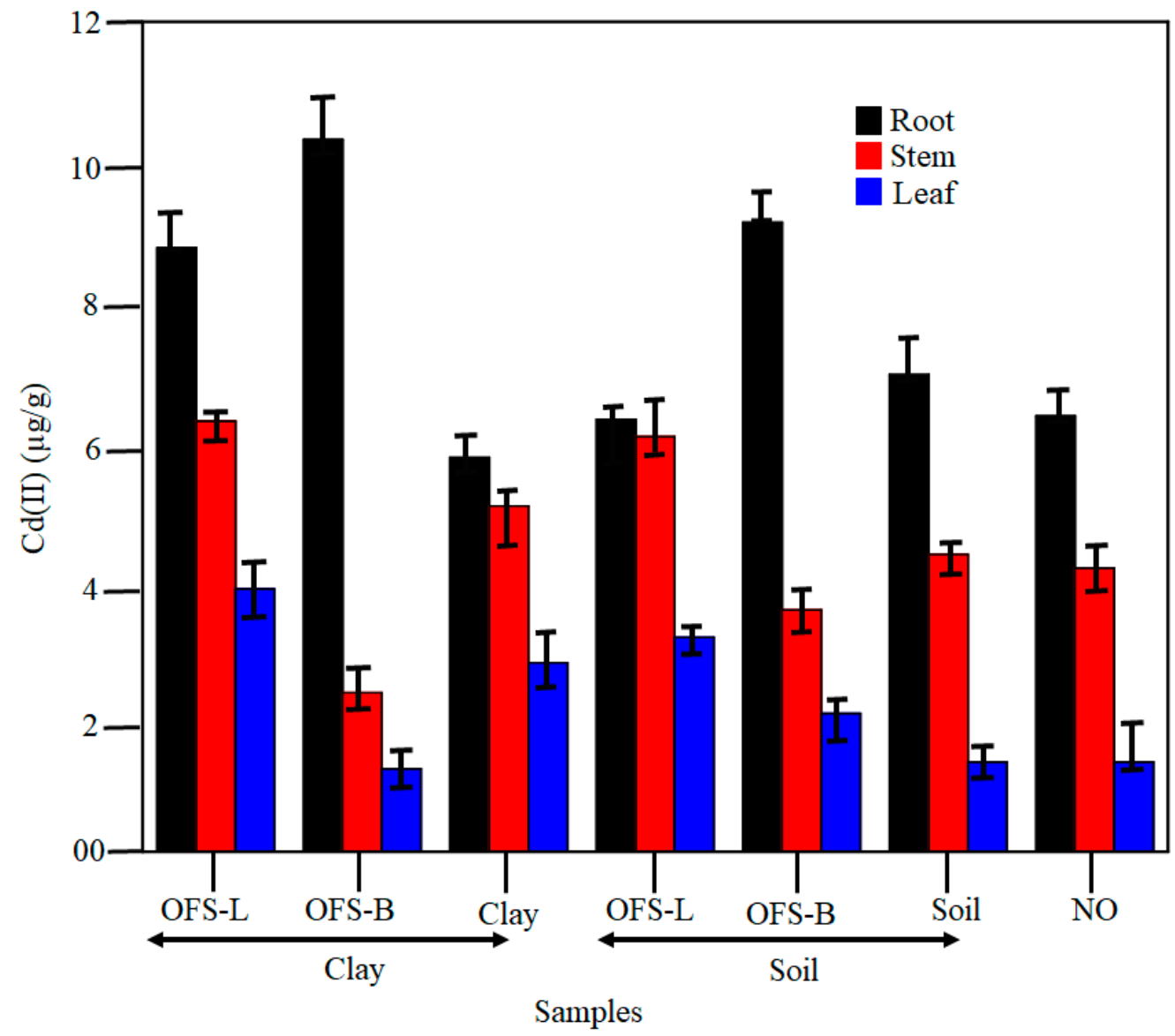

Figure 6. Concentration of Cd (II) in different part of the Cyperus alternifolius plant.

\subsection{Cyperus Alternifolius Plant Analysis}

The purpose of this study was to investigate how a silane-modified clay/soil layer compared to no additional layer affected plant tolerance by assessing biomass, chlorophyll $\mathrm{b}$ content, and observing plant height. The silane-modified clay/soil layer had a substantial impact on the growth of Cyperus alternifolius plants, as shown in Table 3. The amount of biomass in the plant leaf is on the order of Clay OFS-L $>$ Soil OFS-L $>$ Clay $>$ Clay OFS-B $>$ Soil $>$ Soil OFS-B $>$ NO $>$ Fresh. The presence of the heavy metal CD (II) in the system is responsible for the increased amount of dry biomass. Furthermore, the presence of heavy 
metal in plants with hydrophilic clay and soil is significantly higher than hydrophobic clay and soil samples, according to biomass order. Dry biomass in the stems of Cyperus alternifolius plants followed a similar pattern i.e., Clay OFS-L $>$ Soil OFS-L $>$ Soil OFS-B $>$ Soil $>$ Clay OFS-B $>$ Clay $>$ NO $>$ Fresh. The biomass of the root, on the other hand, is in the order Clay OFS-B $>$ Clay OFS-L $>$ Soil OFS-B $>$ Soil OFS-L $=$ Soil $=$ Clay $>$ NO $=$ Fresh . This indicates that the presence of $\mathrm{Cd}$ (II) is higher in the hydrophobic samples. Plant height, on the other hand, is in the same Clay OFS-L $>$ Soil OFS-L $>$ Clay $>$ Soil $>$ Fresh $>$ Clay OFS-B > Soil OFS-B > NO. Plant height is lower in silane-modified clay or soil with OFS-B (benzyl substituents) than in fresh plants. Furthermore, the concentration of chlorophyll $b$ follows the order of Fresh $>$ Clay OFS-L $>$ Clay OFS-B $=$ Clay $>$ Soil OFS-L $>$ Soil OFS-B $>$ Soil $>$ NO. The chlorophyll content of other samples was measured after 15 days of experiments; therefore, fresh plants contain higher chlorophyll $\mathrm{b}$. When comparing 15 -day plant chlorophyll $b$, the OFS-L modified samples have a higher chlorophyll $b$ level. The results clearly demonstrate the effect of hydrophobic and hydrophilic silane-modifiers on adsorption properties. With rainfall, hydrophilic clays can migrate downwards from the first layer to the second till the third layer, whereas hydrophobic clay or soil cannot. Meanwhile, the Cd (II) and their binding sites are carried by the migrating clay or soil. When compared to OFS-B modified clay or soil, this may aid plant root, stem, and leaf uptake, resulting in higher biomass and plant height. The results are consistent with heavy metal adsorption results in bioretention clay/soil samples and are in line with the obtained results of heavy metal adsorption in bioretention clay/soil samples.

Table 3. Cd (II) adsorption effect on the biomass, chlorophyll content, and plant height of Cyperus alternifolius plants during bioretention system.

\begin{tabular}{|c|c|c|c|c|c|}
\hline \multirow{2}{*}{ Sample } & \multicolumn{3}{|c|}{ Dry Biomass (g) } & \multirow{2}{*}{$\begin{array}{l}\text { Chlorophyll b } \\
\text { (mg/g Fresh } \\
\text { Weight) }\end{array}$} & \multirow{2}{*}{$\begin{array}{c}\text { Plant Height } \\
\text { (cm) }\end{array}$} \\
\hline & Root & Stem & Leaf & & \\
\hline Fresh & 1.2 & 6.3 & 3.2 & 2.10 & 32.5 \\
\hline Clay & 1.4 & 6.8 & 4.3 & 1.75 & 33.2 \\
\hline Clay OFS-L & 1.7 & 9.8 & 6.4 & 1.92 & 35.7 \\
\hline Clay OFS-B & 1.8 & 6.9 & 4.1 & 1.75 & 32.1 \\
\hline Soil & 1.4 & 7.0 & 4.0 & 1.25 & 33.0 \\
\hline Soil OFS-L & 1.4 & 7.3 & 4.8 & 1.55 & 34.2 \\
\hline Soil OFS-B & 1.6 & 7.2 & 3.5 & 1.35 & 31.7 \\
\hline $\mathrm{NO}$ & 1.2 & 6.6 & 3.3 & 0.95 & 31.1 \\
\hline
\end{tabular}

\section{Mechanism Analysis}

According to the findings of the above study, the aspect of the additional layer added to the bioretention system has an impact on the Cd (II) removal rate. Furthermore, the wettability of clay and soil is affected by silane alteration, as evident by the above-mentioned data. However, scanning electron microcopy with EDAX was performed on OFS-L and OFS-B modified clay samples to prove structural property correlations. Figure 7A,B shows SEM images of two clays, Clay OFS-L and Clay OFS-B, as well as EDAX mapping of the clays. OFS-B clay has more carbon than OFS-L clay in terms of silane modifier dispersion on the surface. This conclusion is due to the molecular carbon number ration, as OFS-B has more carbon (structural) than OFS-L. However, there is a noticeable variation in certain $\mathrm{Al}$ and $\mathrm{O}$ components. The findings point to the presence of clay structural $\mathrm{Al}$ on the surfaces. Long-chain quaternary ammonium salt modifier enters the interlayer mostly over the surface, according to earlier research. Benzyl substituted quaternary ammonium salt modifier, on the other hand, is mostly left on the surface [27]. In the case of silane-modified clays, similar behavior has been found. EDAX backs up these findings with Si elemental 
measurement. The OFS-B had a higher amount of Si on the surfaces than OFS-L, as can be observed.
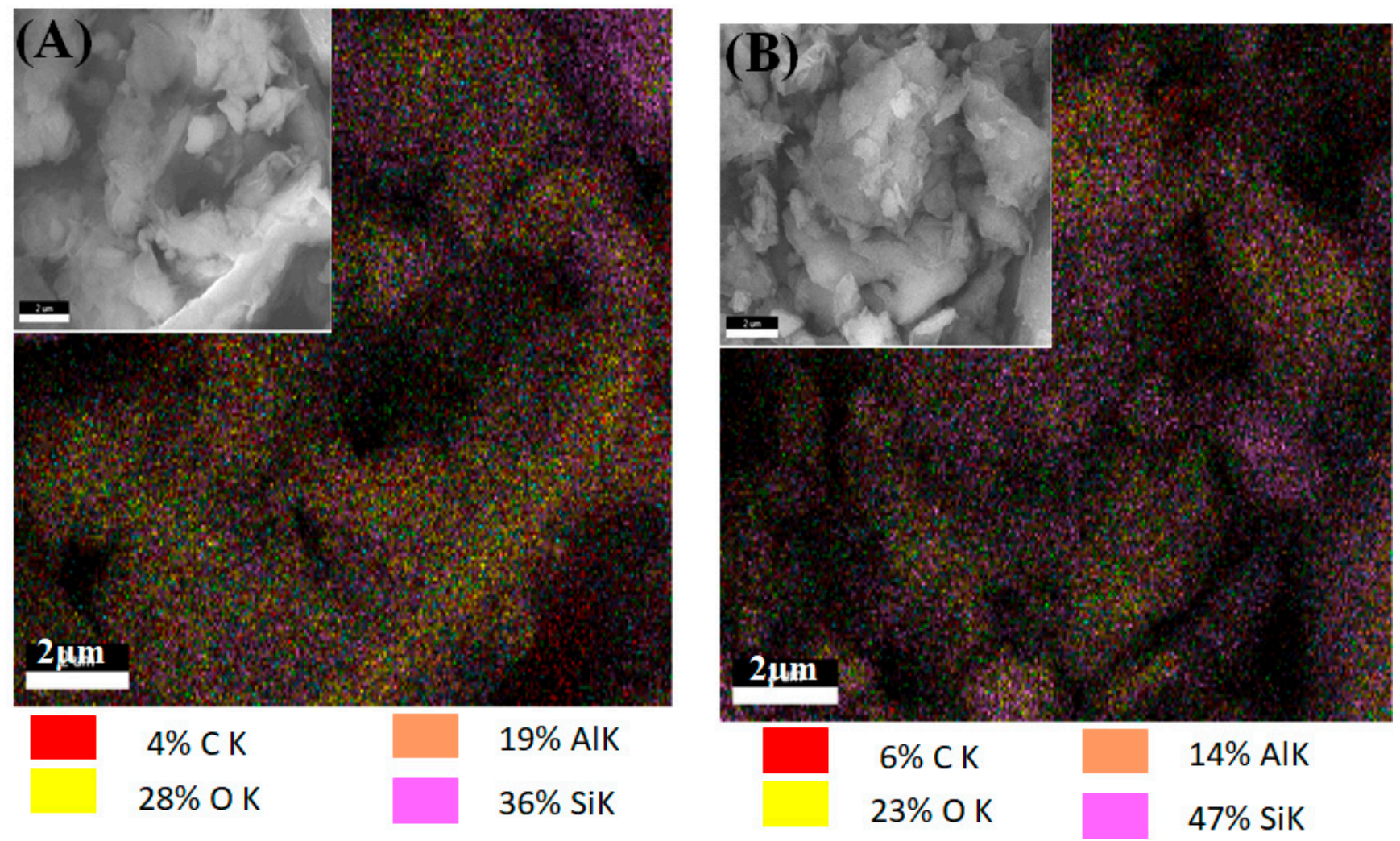

Figure 7. SEM images and EDAX mapping data of (A) OFS-L and (B) OFS-B modified clay.

The bioretention system mechanism has been examined and is schematically represented in Figure 8 after the structural arrangements in clay were completed. Cd (II) adsorption in layer I of the bioretention system is higher in OFS-L modified clay or soil. The stacking of benzyl rings on the clay surfaces, on the other hand, resulted in steric hindrance and steric effects in OFS-B modified clay or soil. The presence of stearic hindrance influences Cd (II) adsorption, causing Cd (II) to move through the interlayer more slowly. As a result, OFS-B modified clay allows water to pass through while remaining non-wettable. At the same time, due to loose stearic force, the clay was leached from layer I to another layer, increasing Cd (II) adsorption in each layer. To put it another way, wettable materials act as a Cd (II) transmission medium or carrier. In non-wettable clay and soil, this process was missing, resulting in aggregation on the surfaces. This is a major reason why OFS-L modified clay removes more Cd (II) than OFS-B modified clay.

Plant uptake has been shown to have similar effects. In general, the plant exhibited capillary rise adsorption, and loosely bound Cd (II) in wettable clay or soil samples had higher uptake, as seen by plant Cd (II) removal and biomass data. Meanwhile, aggregation formed near plant roots with OFS-B modified clay or soil, resulting in a larger amount of $\mathrm{Cd}$ (II) in the root than in other plants. Because of their carrier transforming role in the bioretention system, wettable OFS-A modified clay demonstrated high Cd (II) removal capability, according to the results. 


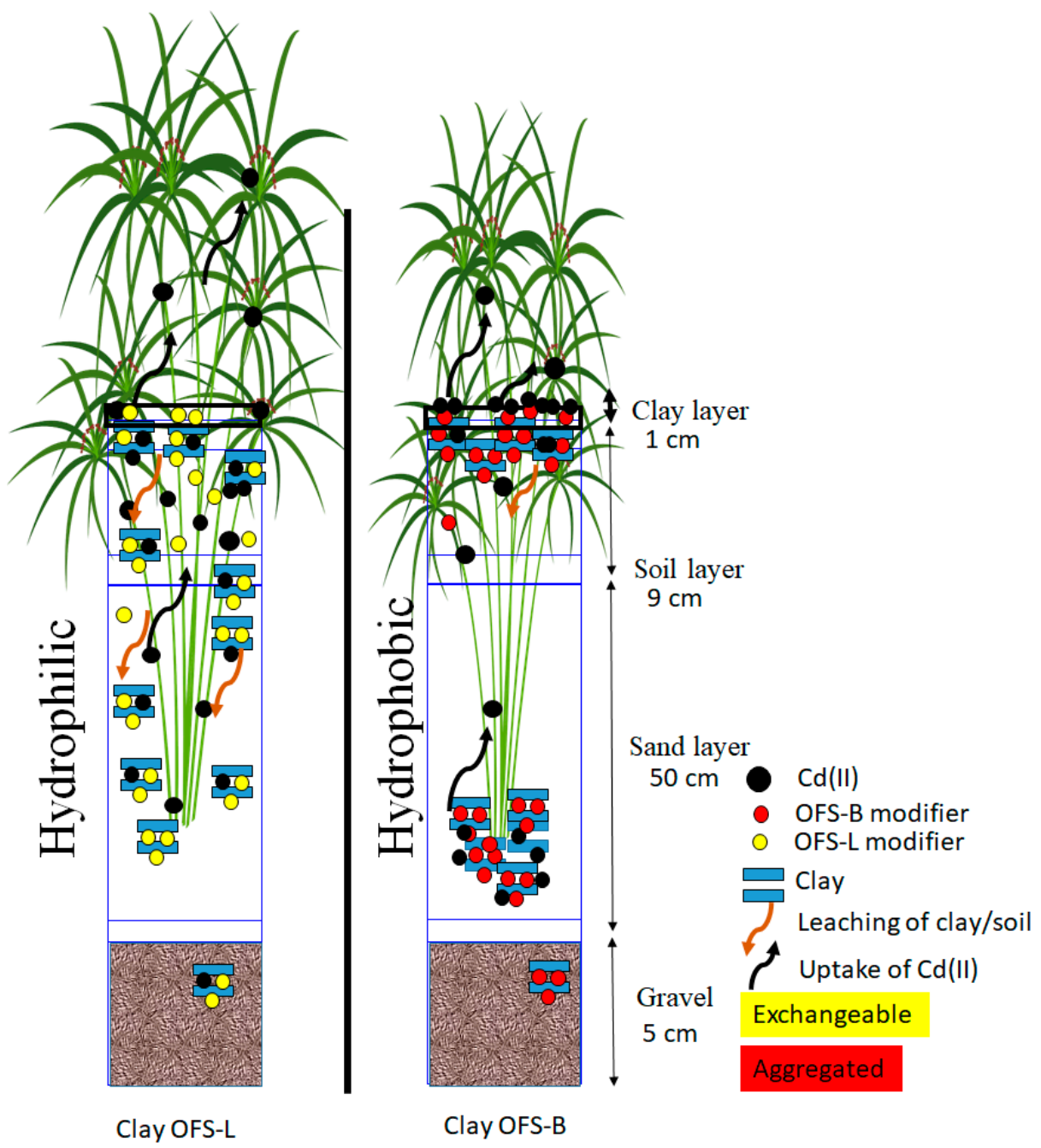

Figure 8. Schematic illustration of movement of Cd (II) in Clay OFS-L (left) and Clay OFS-B (right) incorporated bioretention system.

\section{Conclusions}

In this study, a bioretention system made with an additional clay/soil and silanemodified clay/soil layer removes Cd (II) from simulated rainwater flow. In this study, clay and soil were treated with the linear silane modifier OFS-L and the benzyl-substituted silane modifier OFS-B. Physicochemical studies such as FT-IR, XRD, and contact angle analysis were used to determine the improvement in silane-modified clay and soil properties. Clay and soil modified with the OFS-L modifier had a higher wettability than clay and soil modified with the OFS-B modifier. Therefore, the hydrophobic or non-wettable properties of silane modified clay and soil cannot be guaranteed. On the other hand, an increased $\mathrm{d}$-spacing may be required in order to improve the wettability. The silane modifier OFS-B, on the other hand, prevented this d-spacing, which led to a hydrophobic or non-wettable behavior.

These altered clays and soils are now being used in a bioretention system. To investigate the removal of Cd (II), seven different systems were used including clay, soil, OFS-L clay, OFS-B clay, OFS-L soil, OFS-B soil, and NO. The NO represents a basic bioretention system with no additional layers, whereas the other six systems have a layer of $1 \mathrm{~cm}$ or more. The optimal clearance rate of Cd (II) was recorded on the 3rd day of the rain interval, compared to the 7th and 15th days, after 15 days of testing. Additionally, when compared to OFS-B clay and OFS-L soil, OFS-L had the highest Cd (II) removal capacity. The obtained results clearly reveal that by improving $d$-spacing, the adsorption capacity of OFS-L clay 
was improved. For soil samples, these potential binding sites were absent, and OFS-B prevents them through steric hindrance between existing benzyl substituents. While analyzing the layer samples, it was discovered that OFS-L modified clay improved Cd (II) adsorption in each layer. The leaching properties are responsible for the increased adsorption amount. It is considered that the hydrophilic clay was leached based on the findings. Adsorption in each layer and Cyperus alternifolius plants is improved by adsorbed Cd (II) in the interlayer or outer surface of the clay. The adsorbed Cd (II) improves. Because of the steric effects, benzyl substituted silane (OFS-B) produced agglomerates and did not exhibit this behavior. OFS-L clay improves the quality of Cyperus alternifolius plants by increasing height and preserving chlorophyll $\mathrm{b}$ levels in the leaves, in addition to removing $\mathrm{Cd}$ (II). Due to their steric effects, benzyl substituted silane (OFS-B) did not exhibit this behavior. Of the seven bioretention systems, OFS-L modified clay was more effective than OFS-L modified soil due to its better wettability, availability of binding sites, and d-spacing for $\mathrm{Cd}$ (II) removal. Finally, all results suggest that the selective loading of the material and the configurations of the surface modifier play a significant role in the Cd (II) removal rates.

Supplementary Materials: The following are available online at https://www.mdpi.com/article/10 .3390 /w13223164/s1, Figure S1: FT-IR absorption spectra of (a) clay; (b) clay OFS-B; (c) clay OFS-L; (d) soil; (e) soil OFS-B; (f) soil OFS-L.

Author Contributions: The first author T.X. conceptualized the experiments and wrote the first draft; J.Y. performed experiments, data curation, and the design methodology. D.C. performed analysis and participated in technical discussion. Z.Y. performed visualization and supervision. K.J.S. participated as principal investigator (PI) of the research and organized the data, wrote the manuscript, and submitted it for publication. All authors have read and agreed to the published version of the manuscript.

Funding: This research received no external funding.

Institutional Review Board Statement: Not applicable.

Informed Consent Statement: Not applicable.

Data Availability Statement: The data presented in this study are available on request from the corresponding author.

Conflicts of Interest: The authors declare no conflict of interest.

\section{References}

1. Hoekstra, A.Y.; Chapagain, A.K.; Van Oel, P.R. Advancing water footprint assessment research: Challenges in monitoring progress towards sustainable development goal 6. Water 2017, 9, 438. [CrossRef]

2. Sun, Y.; Shah, K.J.; Sun, W.; Zheng, H. Performance evaluation of chitosan-based flocculants with good pH resistance and high heavy metals removal capacity. Sep. Purif. Technol. 2019, 215, 208-216. [CrossRef]

3. Sakson, G.; Brzezińska, A.; Zawilski, M. Emission of heavy metals from an urban catchment into receiving water and possibility of its limitation on the example of Lodz city. Environ. Monit. Assess. 2018, 190, 1-15. [CrossRef] [PubMed]

4. Wang, J.; Zhao, Y.; Yang, L.; Tu, N.; Xi, G.; Fang, X. Removal of heavy metals from urban stormwater runoff using bioretention media mix. Water 2017, 9, 854. [CrossRef]

5. Davis, A.P.; Shokouhian, M.; Ni, S. Loading estimates of lead, copper, cadmium, and zinc in urban runoff from specific sources. Chemosphere 2001, 44, 997-1009. [CrossRef]

6. Duong, T.T.; Lee, B.K. Determining contamination level of heavy metals in road dust from busy traffic areas with different characteristics. J. Environ. Manag. 2011, 92, 554-562. [CrossRef]

7. Hwang, H.M.; Fiala, M.; Park, D.; Wade, T.L. Review of pollutants in urban road dust and stormwater runoff: Part 1. Heavy metals released from vehicles. Int. J. Urban Sci. 2016, 20, 334-360. [CrossRef]

8. Müller, A.; Österlund, H.; Marsalek, J.; Viklander, M. The pollution conveyed by urban runoff: A review of sources. Sci. Total. Environ. 2020, 709, 136125. [CrossRef]

9. Green Infrastructure for Your Community. Available online: www.deeproot.com/blog/blog-entries/long-term-use-ofbioretention-for-heavy-metals-removal (accessed on 29 May 2021).

10. Li, H.; Davis, A.P. Heavy metal capture and accumulation in bioretention media. Environ. Sci. Technol. 2008, 42, 5247-5253. [CrossRef] 
11. Deliyanni, E.A.; Kyzas, G.; Matis, K.A. Various flotation techniques for metal ions removal. J. Mol. Liq. 2017, 225, 260-264. [CrossRef]

12. Jin, Y.; Luan, Y.; Ning, Y.; Wang, L. Effects and mechanisms of microbial remediation of heavy metals in soil: A critical review. Appl. Sci. 2018, 8, 1336. [CrossRef]

13. Qasem, N.A.A.; Mohammed, R.H.; Lawal, D.U. Removal of heavy metal ions from wastewater: A comprehensive and critical review. Npj Clean Water 2021, 36. [CrossRef]

14. Johnson, P.D.; Girinathannair, P.; Ohlinger, K.N.; Ritchie, S.; Teuber, L.; Kirby, J. Enhanced removal of heavy metals in primary treatment using coagulation and flocculation. Water Environ. Res. 2008, 80, 472-479. [CrossRef] [PubMed]

15. Sun, Y. New class of flocculants and coagulants. In Advances in Wastewater Treatment I; Gandhi, V., Shah, K., Eds.; Materials Research Forum LLC: Washington, WA, USA, 2021; Volume 91, pp. 219-252. [CrossRef]

16. Lakherwal, D. Adsorption of heavy metals: A review. Int. J. Environ. Res. Dev. 2014, 4, 41-48.

17. Beni, A.A.; Esmaeili, A. Biosorption, an efficient method for removing heavy metals from industrial effluents: A Review. Environ. Technol. Innov. 2020, 17, 100503. [CrossRef]

18. Li, G.; Xiong, J.; Zhu, J.; Liu, Y.; Dzakpasu, M. Design influence and evaluation model of bioretention in rainwater treatment: A review. Sci. Total Environ. 2021, 787, 147592. [CrossRef]

19. Davis, A.P.; Hunt, W.F.; Traver, R.G.; Clar, M. Bioretention technology: Overview of current practice and future needs. J. Environ. Eng. 2009, 135, 109-117. [CrossRef]

20. Roy-Poirier, A.; Champagne, P.; Filion, Y. Review of bioretention system research and design: Past, present, and future. J. Environ. Eng. 2010, 136, 878-889. [CrossRef]

21. Boenigk, J.; Wiedlroither, A.; Pfandl, K. Heavy metal toxicity and bioavailability of dissolved nutrients to a bacterivorous flagellate are linked to suspended particle physical properties. Aquat. Toxicol. 2005, 71, 249-259. [CrossRef]

22. Davis, A.P.; Shokouhian, M.; Sharma, H.; Minami, C. Laboratory study of biological retention for urban stormwater management. Water Environ. Res. 2001, 73, 5-14. [CrossRef]

23. Sun, X.; Davis, A.P. Heavy metal fates in laboratory bioretention systems. Chemosphere 2007, 66, 1601-1609. [CrossRef]

24. Salt, D.E.; Smith, R.D.; Raskin, I. Phytoremediation. Annu. Rev. Plant Physiol. 1998, 49, 643-668. [CrossRef]

25. Huang, J.W.; Chen, J.; Berti, A.W.R.; Cunningham, S.D. Phytoremediation of lead-contaminated soils: Role of synthetic chelates in lead phytoextraction. Environ. Sci. Technol. 1997, 31, 800-805. [CrossRef]

26. Gil, A.; Santamaría, L.; Korili, S.; Vicente, M.; Barbosa, L.; de Souza, S.; Marçal, L.; de Faria, E.; Ciuffi, K. A review of organicinorganic hybrid clay based adsorbents for contaminants removal: Synthesis, perspectives and applications. J. Environ. Chem. Eng. 2021, 9, 105808. [CrossRef]

27. Shah, K.; Mishra, M.K.; Shukla, A.D.; Imae, T.; Shah, D.O. Controlling wettability and hydrophobicity of organoclays modified with quaternary ammonium surfactants. J. Colloid Interface Sci. 2013, 407, 493-499. [CrossRef] [PubMed]

28. Gupta, B.; Shah, D.; Mishra, B.; Joshi, P.; Gandhi, V.G.; Fougat, R. Effect of top soil wettability on water evaporation and plant growth. J. Colloid Interface Sci. 2015, 449, 506-513. [CrossRef] [PubMed]

29. Shah, K.J.; Pan, S.Y.; Shukla, A.D.; Shah, D.O.; Chiang, P.C. Mechanism of organic pollutants sorption from aqueous solution by cationic tunable organoclays. J. Colloid Interface Sci. 2018, 529, 90-99. [CrossRef] [PubMed]

30. You, Z.; Zhang, L.; Pan, S.Y.; Chiang, P.C.; Pei, S.; Zhang, S. Performance evaluation of modified bioretention systems with alkaline solid wastes for enhanced nutrient removal from stormwater runoff. Water Res. 2019, 161, 61-73. [CrossRef] [PubMed]

31. Climate Nanjing. Available online: https:/ / en.climate-data.org/asia/china/jiangsu/nanjing-2490/ (accessed on 10 October 2021).

32. Chen, G.; Shah, K.J.; Shi, L.; Chiang, P.C.; You, Z. Red soil amelioration and heavy metal immobilization by a multi-element mineral amendment: Performance and mechanisms. Environ. Pollut. 2019, 254, 112964. [CrossRef]

33. Arnon, D.I. Copper enzymes in isolated chloroplasts. Polyphenoloxidase in Beta vulgaris. Plant Physiol. 1949, 24, 1-15. [CrossRef] [PubMed]

34. Krivoshein, P.K.; Volkov, D.S.; Rogova, O.B.; Proskurnin, M.A. FTIR photoacoustic spectroscopy for identification and assessment of soil components: Chernozems and their size fractions. Photoacoustics 2020, 18, 100162. [CrossRef] [PubMed]

35. Abeywardena, S.B.Y.; Perera, S.; De Silva, K.M.N.; Tissera, N.P. A facile method to modify bentonite nanoclay with silane. Int. Nano Lett. 2017, 7, 237-241. [CrossRef]

36. Wang, Y.; Wang, P.; Kohls, D.; Hamilton, W.A.; Schaefer, D.W. Water absorption and transport in bis-silane films. Phys. Chem. Chem. Phys. 2009, 11, 161-166. [CrossRef] [PubMed]

37. Nandiyanto, A.B.D.; Oktiani, R.; Ragadhita, R. How to Read and Interpret FTIR Spectroscope of Organic Material. Indones. J. Sci. Technol. 2019, 4, 97-118. [CrossRef] 